\title{
Relative Price Dispersion and the Rate of Inflation: The Evidence from J apan
}

\author{
Sean Holly \\ University of Cambridge
}

\begin{abstract}
The relationship between inflation and price variability has been of interest to economists for many years. Recently, Ball and Mankiw [1995] have proposed a menu-cost model of price stickiness in which the skewness of relative price infla tion matters as well as the standard deviation. In this paper their model is test ed on Japanese wholesale price data. The results are mixed. When we use the single equation approach of Ball and Mankiw the results appear to favour their model. However, once we condition inflation on the growth in the money stock and allow for the simultaneity of inflation and relative price variability predict ed by a Lucas type misperceptions model, then the effects postulated by Ball and Mankiw largely disappear, while inflation seems to drive both the standard devi ation and skewness of relative prices. (JE L Classi fication: E 3, F 41)
\end{abstract}

\section{Introduction}

The relationship between inflation and price variability has been of interest to economists for many years. This relationship can take two forms. Firstly, it has been noted by Logue and Willett [1976], among others, that there is a

* Correspondence Address: Department of Applied Economics, University of Cambridge, Austin Robinson Bldg., Sidgwick Avenue, Cambridge, CB3 9DE, England (Tel) 01-223-3352; The research was carried out under ESRC Grant N o. L116251017. We are grateful for the helpful comments of two referees.

(C1997 - Institute for International Economics, Sejong Institution. All rights reserved. 
positive correlation between the level of inflation and the variability of inflation. High inflation may also mean that inflation is less predictable. The second type of relationship concerns that between the level of inflation and the variability of relative prices. A positive correlation was first obser ved by M ills [1927] in his study of American prices, while Graham [1930] ${ }^{1}$ found a similar relationship during the German hyperinflation of the early 1930s. Glejser [1965] later found that this pattern was also observable in 15 European countries. In this paper we concentrate on the relationship between relative price variability and inflation. Recently there has been a number of theoretical attempts to explain this empirical finding. These have tended to fall into two categories. There is the incomplete-information model of Lucas, for example, used by Cukierman and Wachtel [1979] and Cukierman [1979] which predicts a positive association between the level of inflation and the variability of relative prices. Cukierman shows that the positive relationship is quite consistent with the many-markets, stochastic model of Lucas. In this framework both the variance of relative prices and changes in the aggregate price level are affected by common exogenous variances such as the variance of aggregate excess demand shocks and the variance of relative excess demand shocks M ore recently Reindorf [1994] has argued that while the level of expected inflation is positively related to relative price dispersion unexpected inflation is negatively related to price dispersion.

The second approach emphasizes the role of menu costs of changing prices. Schultze [1959] and Tobin [1972] allow changes in the variability of relative prices to affect the aggregate rate of inflation. If prices are inflexible in a downward direction, or in other words there is an asymmetric price response, then changes in the variability of relative prices will be reflected in the aggregate inflation rate.

The most recent version of this model is due to Ball and M ankiw [1995]. ${ }^{2}$ Their approach differs in a number of significant ways from earlier menu

1. There have been numerous empirical studies such as B atchelor(1981), Balk(1978), Blejer(1983), Clements and N guyen [1981], Fischer [1982], Herkowitz [1981], Logue and Willett [1976], M izon, Safford and Thomas [1990], Parks [1978], Vining and Elwertowski [1976], and Taylor [1981].

2. For other theoretical discussions see Lilien [1982], Sheshinski and Weiss [1981], Tobin [1972], Tsiddon [1991, 1993]. 
cost models. They develop a model in which it is not the variability, per se, in relative price dispersion which matters for aggregate inflation but the asymmetry of shocks to individual prices. If there are costs to changing prices and different firms experience a series of random shocks, there will be a range of inaction within which it is not worthwhile bearing the cost of changing prices. If the shocks are normally distributed, on average some firms will experience negative shocks while others will experience positive shocks. These shocks can be both to demand and to cost conditions. An increase in the variability of these shocks should not affect the aggregate price index, which is the average of the individual prices. On average abnormally large negative shocks will be offset by abnormally large positive shocks, leaving the price level unaffected. However, if the shocks to demand and costs are skewed, then for positively skewed shocks the price level will rise, since on average more firms are raising their prices than are reducing them; while if the shocks are negatively skewed more firms will be reducing prices than raising them and the price level will fall.

In the B all-M ankiw model the variance of relative prices only matters if an increase in variance coincides with a skewed shock. In this case an increase in variance amplifies the effect of an increase in skewness. In the Cukierman model, by contrast, the correlation between inflation and relative price variability arises from the possibility that the variance of the changes in the price level and the variance of individual price changes reflect the effects of common exogenous variances such as the variance of excess demand shocks and the variance of relative excess demand shocks, Ball and M ankiw attribute a distinctly independent role to the skewness of shocks with causality clearing running from a skewed shock to relative prices to the aggregate price level. So when there are costs associated with changing prices - so firms respond proportionately more to large shocks - then relative price shocks can shift the short run Phillips curve.

It is important to note that Ball and Mankiw develop their model - for simplicity - by assuming that core inflation is zero so in principle a Cukierman effect will not be present. However, given that empirically core inflation has not been zero for the majority of countries since the second world war we have to allow for the possibility that a positive association between the variance of price dispersion and the level of inflation will be observed. 
We use data on disaggregated wholesale prices in Japan in order to study the role of the dispersion of relative prices in the inflationary mechanism. We find when we use the regression approach of Ball and M ankiw, that the skewness and the product of skewness and standard deviation of relative prices matters rather than the variance on its own - in agreement with the predictions of the Ball-M ankiw model. This evidence is in support of menu cost models rather than the incomplete information model of Cukierman and suggests that our understanding of the short run behavior of output and prices will be enhanced if we acknowledge the role that skewed shocks to relative prices can have. In order to enrich the model we then condition inflation on prior growth in a narrow measure of the money stock in Japan and still appear to find that only skewness and the product term matter for inflation. However, we also look more closely at the simultaneous relationship between inflation and the dispersion of relative prices using both Granger Causality tests and three-stage least squares. We find with the causality tests that inflation 'Granger-Causes' the variance of relative prices but is not itself 'Granger-Caused' by the variance of relative prices. A similar result is observed for the skewness of relative price inflation. These results seem to suggest that much of the causality flows from inflation to the dispersion of relative prices rather than as in the Ball-M ankiw model where there is an independent effect of the skewness of relative prices on inflation. However, as is well known, Granger-Causality tests do not take any account of contemporaneous correlations. But they do suggest that the inter-relationships between inflation and the higher moments of the dispersion of relative price inflation is more complex than suggested by the regression results. We, therefore, estimated a joint model for inflation, the standard deviation and the skewness of relative prices. We find that the Ball-M ankiw model does not work very well with only a marginally significant lagged effect of skewness on inflation. Causality appears to flow largely from inflation to the higher moments of relative prices.

\section{The Ball-Mankiw Model}

Ball and M ankiw [1995] use a menu cost framework but develop a model in which it is not the variability per se of relative prices but rather the asym- 
metric behavior of relative prices. If there are costs associated with changing prices and there is a random shock, firms will face a range of inaction within which it will not be worthwhile to alter output prices. These shocks can be either to demand or supply. If shocks across firms are randomly distributed then an increase in the variability of these shocks should not affect the average of firm prices - the price level - since abnormally large negative shocks will be offset by abnormally large positive shocks.

However, if the shocks are skewed then for a positively skewed shock, the average price level will rise since on average more firms will be raising their prices than reducing them. The variance of relative prices will only matter in so far as if an increase in the variance of relative prices coincides with an increase in skewness then the effect of a skewed shock will be magnified. $^{3}$

They formalize this using a menu-cost model. The economy is assumed to be made up of a continuum of industries, each industry comprising a continuum of imperfectly competitive firms. Each industry has a common desired price. Initially there is a state of equilibrium with desired prices equal to actual prices. All prices, in logs, are normalized to zero. Each industry then experiences a disturbance in the form of a shift in demand or a change in costs. The desired price is now $q$. The mean-zero shock, q, has a density function $\mathrm{f}(\cdot)$ across industries, so the average price level is unaffected if all prices adjust.

If prices are changed a menu cost, $C$, must be paid. The cost of not changing prices is quadratic in the disturbance, $\theta^{2}$. So the firm adjusts its price only if $|\theta|>\sqrt{\mathrm{C}}$. It is assumed that within an industry menu costs vary between firms so $\sqrt{C}$ has a distribution $G(\cdot)$. An industry price change is the mean of the change in firm prices, and inflation is then the mean of the industry changes. In this situation the distribution of shocks will affect aggregate inflation. For an industry that experiences a shock, , the proportion of firms that will adjust their prices, that is those with $\sqrt{C}<|\theta|$, will be $G(|\theta|)$. Since these firms adjust their prices by the full amount of the distur-

3. Ball and M ankiw acknowledge that a number of previous authors have noticed a correlation between inflation and the skewness of relative price inflation, for example, Batchelor [1981], B lejer [1983] and M izon, Safford and Thomas [1990]. However, Ball and M ankiw's is the first attempt to provide a theoretical explanation. 
bance, the price index for the industry changes by $G(|\theta|)$. Inflation, $\pi$, is then the average of the change in industry prices. So:

$$
\begin{aligned}
& =\sum_{-\infty}^{\infty} G(||) f() d \\
& =\sum_{0}^{\infty} G()[f()-f(-)] d
\end{aligned}
$$

If the density function of the disturbances is symmetric about zero, then $f(\theta)$ is obviously equal to $f(-\theta)$ so inflation is zero. However, when $f(\theta)$ is asymmetric disturbances that affect relative prices will affect the aggregate inflation rate. Ball and $\mathrm{M}$ ankiw go on to demonstrate that it is not the standard deviation but the skewness of relative price changes that matter for the inflation rate. Although the variance has no independent effect on inflation it interacts positively with skewness. A large variance is inflationary when the disturbance is skewed to the right and deflationary when it is skewed to the left.

A crucial feature of the BM model is that the core rate of inflation is zero. When the core rate of inflation is not zero, then we have to consider the possibility that some of the other models proposed may be appropriate also. Furthermore, the direction of causation may become ambiguous. In the model of Cukierman [1979], for example, a general inflationary shock may initially manifest itself as an increase in the variability of relative prices because there are differing degrees of persistence of relative price shocks across industries and different interpretations will be placed on a transitory shock with corresponding differential supply and price responses.

As Cukierman shows, in a frictionless world, when prices clear markets immediately - where a rise in one price should be associated with a fall in some other price - we will observe a correlation between the price level and the variability of relative prices as long as there is uncertainty about both sector-specific shocks and shocks to the aggregate price level. In the many-markets, stochastic model of Lucas, there will be a positive association between the dispersion of relative prices and the rate of inflation. However, the causation does not run from the instability of the price level to the variability of relative price changes. Rather both the variance of changes in the price level and the variance of individual price changes are influenced by some common exogenous variances like the variance of excess demand shocks and the vari- 
ance of relative excess demand shocks. In this framework with both being determined simultaneously the notion of causality is ambiguous.

\section{Empirical Results}

In this section we test the B all-M ankiw model for Japan over the period 1976-1994. We have used quarterly data on wholesale prices in 17 industries. Japan is an interesting case because as can be seen in Chart 1 there have been a number of periods when inflation has been negative. In fact, the average rate of inflation over this sample is only 0.19 percent. Since the Ball$M$ ankiw model specifically assumes the core rate of inflation is zero this seems a particularly appropriate data set with which to test their model. In Chart 2 we have plotted the standard deviation of relative inflation rates. The chart is clearly dominated by the large shock of the late 1970s and early 1980s associated with the rise in world oil prices. In Chart 3 we show the skewness of these relative price changes. There is a significant period of positive skewness in the late 1970s, early 1980s and a number of periods of negative skewness in the mid 1980s, partly associated with the fall in oil prices in 1985-86 but also with periods of exchange rate volatility. In Chart 4 we plot the product of the standard deviation and skewness. Again, the most significant period during which high variance coincided with a skewed distribution in relative price inflation was in the late 1970s - early 1980s, and then to a lesser extent in the mid-1980s, and intermittently during the 1990s.

\section{A. Causality Testing}

The charts above describe the basic facts. In our empirical examination we begin with a statistical analysis using Granger causality tests. As is well known this approach tells us nothing about the contemporaneous correlations but in a dynamic model it may be suggestive of how the variables in the model interact over time. In Table 1 we first report a set of pair-wise causality tests using Granger's approach. We are, therefore, ignoring any possible contemporaneous correlation between inflation and measures of relative price dispersion. The results suggest that inflation Granger-causes the standard deviation of relative price inflation but is not itself caused by 


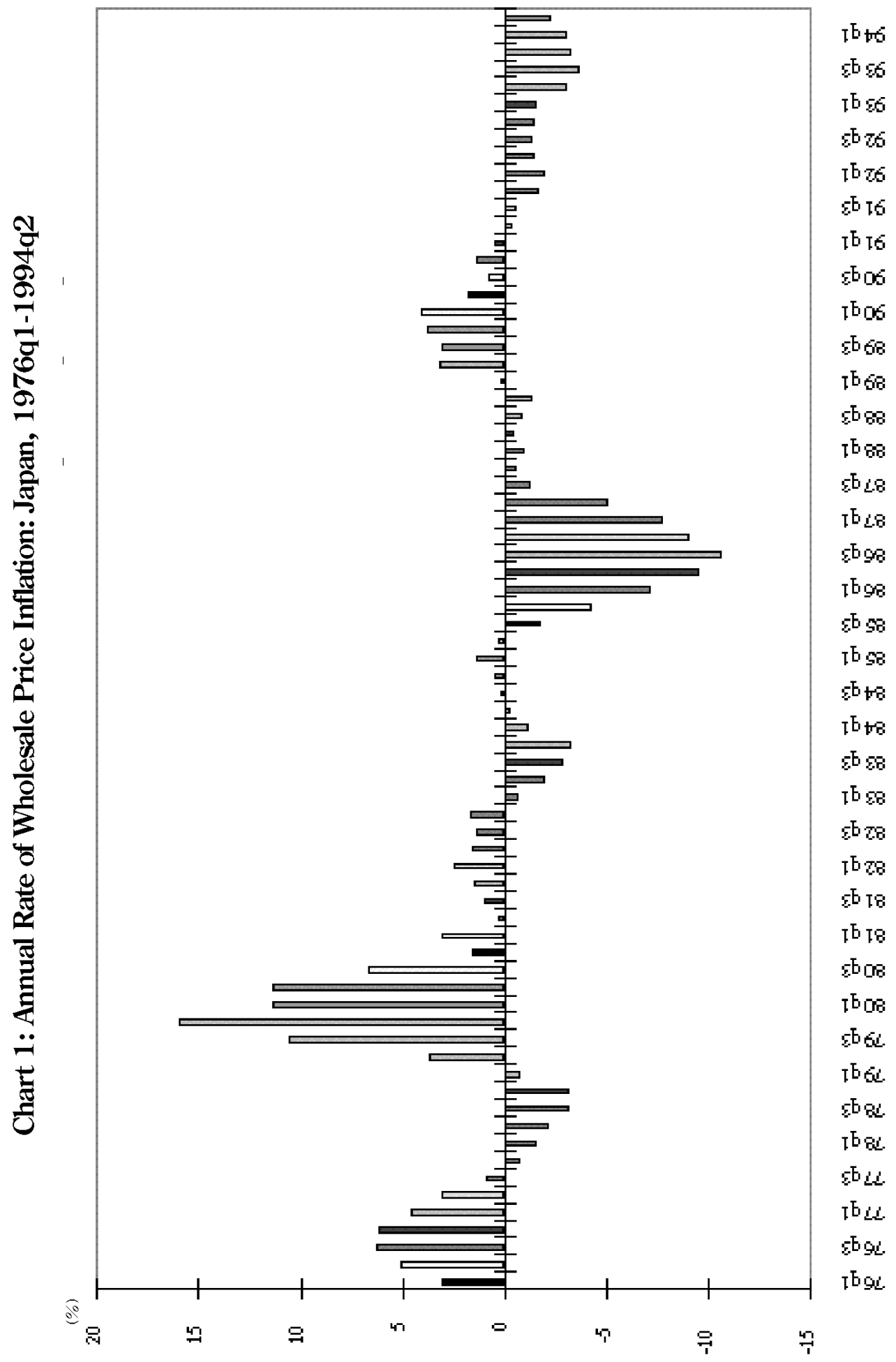




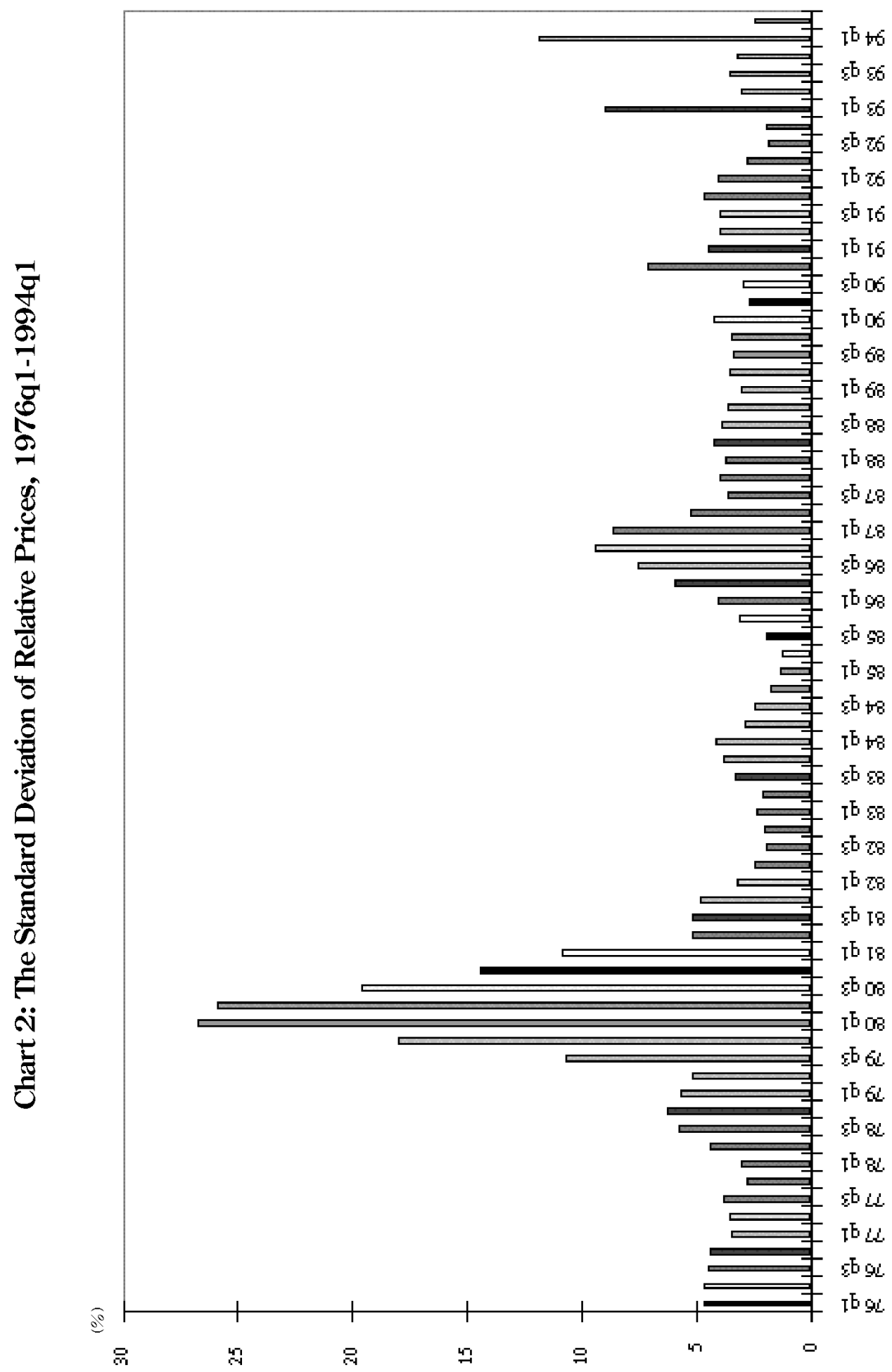




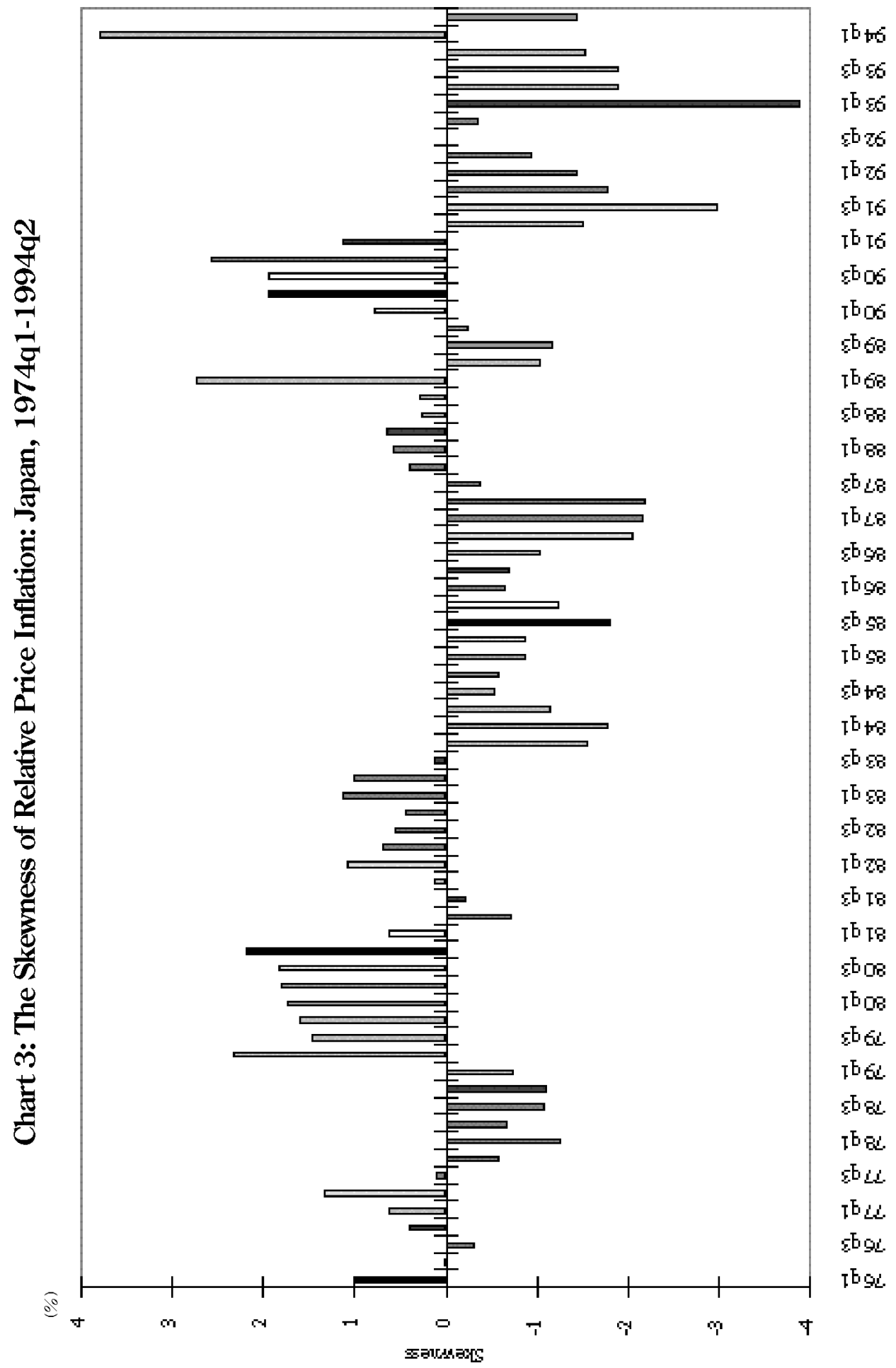


Relative Price Dispersion and the Rate of I nflation: The Evidence from J apan

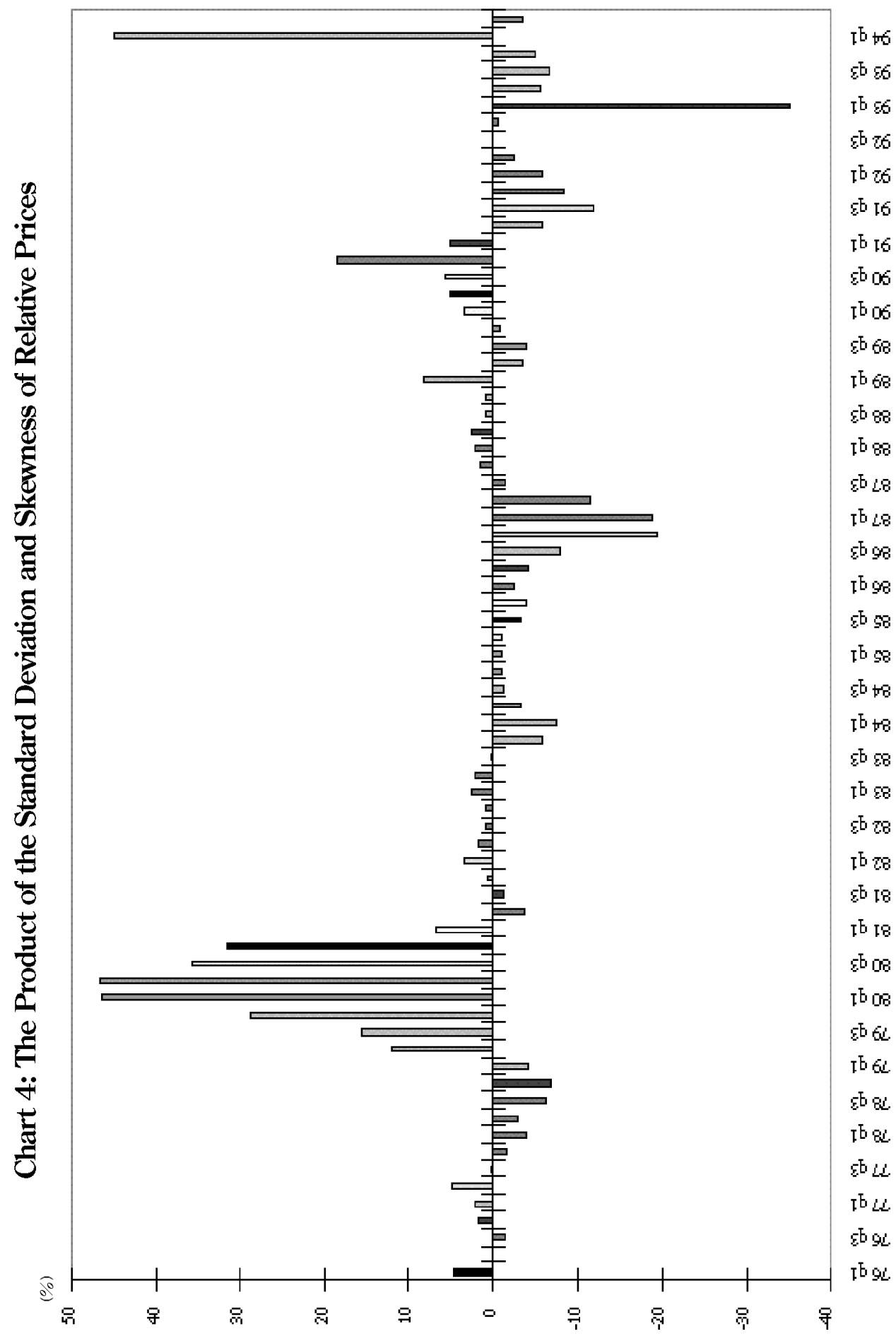




\section{Table 1}

\section{Pair-wise Granger Causality Tests}

Sample: 1976:1 1994:2 Lags: 4

\begin{tabular}{|l|c|c|}
\hline \multicolumn{1}{|c|}{ Null Hypothesis: } & F-Statistic & Probability \\
\hline$\sigma$ does not Granger Cause $\pi$ & 0.11827 & 0.97552 \\
$\pi$ does not Granger Cause $\sigma$ & 2.32514 & 0.06642 \\
\hline$v$ does not Granger Cause $\pi$ & 0.84702 & 0.50094 \\
$\pi$ does not Granger Cause $v$ & 2.56442 & 0.04708 \\
\hline$\sigma v$ does not Granger Cause $\pi$ & 0.58202 & 0.67680 \\
$\pi$ does not Granger Cause $\sigma v$ & 7.21794 & $8.0 \mathrm{E}-05$ \\
\hline$v$ does not Granger Cause $\sigma$ & 0.92975 & 0.45273 \\
$\sigma$ does not Granger Cause $v$ & 1.09930 & 0.36510 \\
\hline
\end{tabular}

relative price variability. A similar result obtains for skewness. For the product of the standard deviation and skewness, again inflation Granger-causes it, However, the product term does not cause inflation. Interestingly there is no causal relationship between skewness and standard deviation. These results seem to suggest that much of the causality flows from inflation to the dispersion of relative prices in contradiction of the Ball-M ankiw model which ascribes an independent effect of the skewness of relative prices on inflation. However, we are ignoring the contemporaneous correlations and the possibly multivariate nature of the relationship between the inflation rate and the moments of the dispersion of relative prices. We shall come back to this issue later.

\section{B. The Basic Ball-Mankiw Model}

The next issue is to test the Ball-M ankiw model as they do (Ball and $M$ ankiw, 1995) on this Japanese data set. To do this we first follow their procedure of regressing inflation on lags of itself - to capture the persistent nature of the inflationary process ${ }^{4}$ - , and on the higher moments of the dis-

4. It is worth noting in passing that all of the variables that we are considering are stationary, i.e., I(0). 
Table 2

Inflation and the Variability of Relative Prices

(Dependent Variable: $\Delta \pi$ )

\begin{tabular}{|l|c|c|c|c|c|}
\hline & $(1)$ & $(2)$ & $(3)$ & $(4)$ & $(5)$ \\
\hline Constant & -0.1891 & -0.1321 & -0.2734 & 3.6588 & 3.8163 \\
& $(0.90)$ & $(0.58)$ & $(1.30)$ & $(2.80)$ & $(3.07)$ \\
$\pi_{\mathrm{t}-1}$ & 1.5087 & 1.4416 & 1.4587 & 1.3351 & 1.3344 \\
& $(17.90)$ & $(16.08)$ & $(16.24)$ & $(14.67)$ & $(14.90)$ \\
$\pi_{\mathrm{t}-2}$ & -0.6689 & -0.6268 & -0.6539 & -0.6184 & -0.6267 \\
& $(8.78)$ & $(8.33)$ & $(8.80)$ & $(8.55)$ & $(9.04)$ \\
$\sigma_{\mathrm{t}}$ & 0.1617 & 0.1050 & 0.1023 & 0.0913 & 0.0824 \\
& $(3.49)$ & $(2.07)$ & $(2.73)$ & $(1.90)$ & $(2.22)$ \\
$\sigma_{\mathrm{t}-1}$ & -0.0996 & -0.0446 & & -0.0176 & \\
& $(2.05)$ & $(0.84)$ & & $(0.35)$ & \\
$v_{\mathrm{t}}$ & & -0.3064 & & -0.3264 & -0.3198 \\
& & $(1.55)$ & & $(1.74)$ & $(1.74)$ \\
$v_{\mathrm{t}-1}$ & & 0.5123 & 0.3982 & 0.3986 & 0.4137 \\
& & $(2.62)$ & $(2.62)$ & & $(2.33)$ \\
$(\sigma \cdot v)_{\mathrm{t}}$ & & 0.0595 & 0.0254 & 0.0627 & 0.0627 \\
& & $(2.22)$ & $(1.90)$ & $(2.12)$ & $(2.53)$ \\
$(\sigma \cdot v)_{\mathrm{t}-1}$ & & -0.0590 & -0.0515 & -0.0425 & -0.0453 \\
& & $(2.22)$ & $(2.39)$ & $(1.65)$ & $(1.93)$ \\
$\mathrm{u}_{\mathrm{t}}$ & & & & -2.0124 & -1.6931 \\
& & & & $(1.78)$ & $(3.28)$ \\
$\mathrm{u}_{\mathrm{t}-1}$ & & & & 0.3996 & \\
& & & & $(0.35)$ & \\
\hline $\mathrm{R}^{2}$ & & & & 0.96 & 0.97 \\
$\mathrm{SEE}$ & 0.95 & 0.95 & 0.95 & 0.903 & 0.890 \\
$\mathrm{DW}$ & 1.003 & 0.958 & 0.953 & 1.90 \\
$\mathrm{SC}(4)$ & 1.81 & 1.90 & 1.90 & 2.00 & 1.98 \\
$\mathrm{FF}(1)$ & 8.24 & 6.44 & 8.56 & 6.83 & 7.43 \\
$\mathrm{~N}(2)$ & 1.54 & 1.16 & 1.41 & 1.52 & 1.17 \\
$\mathrm{H}(1)$ & 2.05 & 2.34 & 2.43 & 1.16 & 1.28 \\
\hline $\mathrm{Estimation}$ & 0.353 & 0.281 & 0.005 & 0.042 & 0.091 \\
Period & $76 q 3-$ & $76 q 3-$ & $76 q 3-$ & $76 \mathrm{q} 3-$ & $76 \mathrm{q} 3-$ \\
& $94 q 2$ & $94 q 2$ & $94 q 2$ & $94 q 2$ & $94 \mathrm{q} 2$ \\
\hline
\end{tabular}

Notes: Absolute value of t-statistic in brackets. $\sigma$ is the standard deviation and $v$ the skewness of relative prices. SEE is the equation standard error, $\mathrm{SC}(4)$ is a Lagrange M ultiplier test for up to fourth order serial correlation distributed as $\chi^{2}(4)$; FF is Ramsey's test of functional form distributed as $\mathrm{F} ; \mathrm{N}$ is a test of the normality of the residuals, distributed as $\chi^{2}(2) ; H$ is a test for heteroscedasticity, distributed as $a \chi^{2}(1)$. 
tribution of relative price inflation.

In Table 2 we report some regressions along the lines of those provided by Ball and M ankiw with US data. In order to cater for persistence in the inflation rate we include 2 lags in the inflation rate and one lag in the other terms. ${ }^{5}$ In column (1) we provide estimates of a simple relationship between inflation and the standard deviation of relative price inflation. $N$ otwithstanding the causality tests above, there appears to be a strong positive contemporaneous relationship between inflation and the standard deviation. In column (2) we have included current and lagged values of the skewness of relative inflation rates and the product of skewness and standard deviation. In this case the standard deviation of inflation is still significant. However, only the lagged skewness term is marginally significant. We simplified this equation by dropping insignificant terms, one by one and obtained the more parsimonious format in Column (3). The standard deviation has been retained and both the lagged skewness and the product terms are significant, providing some confirmation of the Ball-M ankiw model for the Japanese economy.

It is possible to link these empirical findings, as Ball and Mankiw do to a more conventional relationship such as the Phillips Curve. In Column (4) of Table 1 we have included a term in the rate of unemployment, current and lagged with the original terms shown in Column (3). In column (5) we report a more parsimonious representation. The rate of unemployment appears significant and the current skewness term is now marginally significant. However, the product of skewness and standard deviation is still very significant. Overall, these results seem to suggest that the Ball-M ankiw findings for the US of the importance of the higher moments of the distribution of relative prices are also important for Japan.

\section{Alternative Measures of Asymmetry}

In the Ball-M ankiw model inflation depends effectively on the size of the tails of the distribution of relative price inflation. They, therefore, propose a composite measure which combines the direct effect of skewness with the amplifying effect of the variance. We report the results of using two mea-

5. Initial testing of a more unrestricted dynamic model suggested that this was appropriate. 
Table 3

Inflation and The Variability of Relative Prices:

Alternative Measures of Asymmetry

(D ependent Variable: $\pi_{t}$ )

\begin{tabular}{|c|c|c|c|c|}
\hline & (1) & (2) & (3) & (4) \\
\hline Constant & $\begin{array}{l}0.1058 \\
(0.85)\end{array}$ & $\begin{array}{l}0.1165 \\
(0.88)\end{array}$ & $\begin{array}{l}4.3603 \\
(1.42)\end{array}$ & $\begin{array}{r}4.150 \\
(2.59)\end{array}$ \\
\hline$\pi_{t-1}$ & $\begin{array}{l}1.4839 \\
(15.32)\end{array}$ & $\begin{array}{l}1.5096 \\
(16.84)\end{array}$ & $\begin{array}{c}1.3368 \\
(12.86)\end{array}$ & $\begin{array}{c}1.4419 \\
(14.47)\end{array}$ \\
\hline$\pi_{t-2}$ & $\begin{array}{l}-0.6305 \\
(8.06)\end{array}$ & $\begin{array}{l}-0.6698 \\
(8.37)\end{array}$ & $\begin{array}{l}-0.6245 \\
(8.32)\end{array}$ & $\begin{array}{l}-0.6764 \\
(8.25)\end{array}$ \\
\hline $\begin{array}{l}\text { Asym } 10_{t} \\
\text { Asym } 10_{t-1}\end{array}$ & $\begin{array}{l}0.01797 \\
(3.95) \\
-0.0141 \\
(2.99)\end{array}$ & & $\begin{array}{l}0.00189 \\
(4.33) \\
-0.0072 \\
(0.23)\end{array}$ & \\
\hline Asym5 $_{t}$ & & $\begin{array}{l}0.0111 \\
(2.20)\end{array}$ & & $\begin{array}{l}0.0125 \\
(2.53)\end{array}$ \\
\hline & & $\begin{array}{l}-0.0132 \\
(2.65)\end{array}$ & & $\begin{array}{l}-.0072 \\
(1.36)\end{array}$ \\
\hline$u_{t}$ & & & $\begin{array}{l}-1.7581 \\
(1.46)\end{array}$ & $\begin{array}{l}-1.9937 \\
(1.54)\end{array}$ \\
\hline$u_{t-1}$ & & & $\begin{array}{l}0.0741 \\
(0.01)\end{array}$ & $\begin{array}{l}0.3150 \\
(0.25)\end{array}$ \\
\hline $\mathrm{R}^{2}$ & 0.96 & 0.95 & 0.96 & 0.96 \\
\hline SEE & 0.987 & 1.055 & 0.935 & 1.016 \\
\hline DW & 2.02 & 1.93 & 1.98 & 1.94 \\
\hline $\mathrm{SC}(4)$ & 13.82 & 14.53 & 14.67 & 14.61 \\
\hline$F F(1)$ & 2.52 & 0.008 & 1.08 & 0.04 \\
\hline$N(2)$ & 11.47 & 17.31 & 7.89 & 11.29 \\
\hline$H(1)$ & 11.52 & 9.84 & 11.45 & 12.31 \\
\hline $\begin{array}{l}\text { Estimation } \\
\text { Period }\end{array}$ & $\begin{array}{l}76 q 3- \\
94 q 2\end{array}$ & $\begin{array}{l}76 q 3- \\
94 q 2\end{array}$ & $\begin{array}{l}76 q 3- \\
94 q 2\end{array}$ & $\begin{array}{l}76 q 3- \\
94 q 2\end{array}$ \\
\hline
\end{tabular}

See N otes to Table 2.

sures, one with a cut-off point of $\pm 5 \%$ and one with a cut-off of $\pm 10 \%$ These results are shown below in Table 3. Both asymmetric terms are significant but neither provides a better fit than those shown in Table 2 and there is widespread evidence of mis-specification suggested by the tests for serial correlation, normality and heteroscedasticity. 


\section{A Monetary Attractor}

In this section we return to the issue of a possibly simultaneous relationship between inflation and relative price variability. We also try to enrich the Ball-Mankiw model by conditioning inflation on the rate of growth of the money supply since this is actually a underlying element of their theoretical model. So In order to strengthen the robustness of the empirical results we augmented the model of Table 2 which focuses on the role of relative prices with a narrow measure (M1) of the rate of growth of the money stock. We started initially with a general, unrestricted form and simplified to obtain the result in Table 4 The money variable proved to be a very significant determinant of the inflation rate and below in Table 4, we show the model specified in error correction form, ${ }^{6}$ with the change in inflation as the dependent variable. A test of the restriction that the relationship between inflation and money growth is proportional gave a $\chi^{2}(1)$ test of this restriction of 0.404 , clearly accepting it. Skewness and the product of skewness and standard deviation still appear to have a significant effect on the inflation rate. Taken at face value this appears to provide even stronger confirmation of the BM model. When we condition on the money stock, the dispersion of prices still matters.

\section{Table 4}

\section{Inflation with a Monetary Attractor}

\begin{tabular}{|c|c|c|c|c|}
\hline \multicolumn{5}{|c|}{ 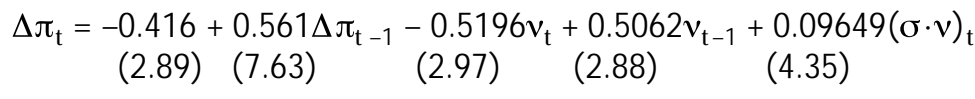 } \\
\hline \multicolumn{5}{|c|}{$\begin{array}{ll}-0.04700(\sigma \cdot v)_{t-1} & -0.1997\left(\pi_{t-1}-\Delta m_{t-1}\right) \\
(2.03) & (5.50)\end{array}$} \\
\hline$R^{2}$ & $=.74$ & $\mathrm{SEE}=.912$ & DW & $=1.87$ \\
\hline $\mathrm{SC}(4)$ & $=6.66$ & $F F(1)=2.359$ & $N(2)$ & $=3.73$ \\
\hline$H(1)$ & $=0.012$ & & & \\
\hline
\end{tabular}

6. It is usual to think of error correction models in the context of non-stationary time series and cointegration. However, here we are using the approach with a set of stationary variables. 


\section{E. Testing Simultaneity}

There still remains an issue of simultaneity between the inflation term and the measures of relative price variability. We do not feel that it is appropriate to use a VAR approach as does Fischer [1982], for example. When we estimated an unrestricted VAR and examine the residual correlation matrix shown in Table 5 below, there is clear evidence of considerable contemporaneous correlation. The usual methods for identifying VARs which involve imposing a prior casual ordering are clearly inappropriate for what we are trying to do in this paper.

Instead we specify a three equation system in an relatively unrestricted form.

$$
\begin{aligned}
& \Delta \pi_{\mathrm{t}}= \alpha_{0}+\alpha_{1} \Delta \pi_{\mathrm{t}-1}+\alpha_{2}\left(\pi_{\mathrm{t}-1}-\Delta \mathrm{m}_{\mathrm{t}-1}\right)+\alpha_{3}(\sigma)_{\mathrm{t}}+\alpha_{4}(\sigma)_{\mathrm{t}-1} \\
&+\alpha_{5} v_{\mathrm{t}}+\alpha_{6} v_{\mathrm{t}-1}+\alpha_{7}(\sigma \cdot v)_{\mathrm{t}}+\alpha_{8}(\sigma \cdot v)_{\mathrm{t}-1} \\
& \sigma_{\mathrm{t}}= \beta_{0}+\beta_{1} \sigma_{\mathrm{t}-1}+\beta_{2} \sigma_{\mathrm{t}-2}+\beta_{3} \pi_{\mathrm{t}}+\beta_{4} \pi_{\mathrm{t}-1}+\beta_{5} \Delta \mathrm{m}_{\mathrm{t}-1}+\beta_{6} \Delta \mathrm{m}_{\mathrm{t}-1} \\
& v_{\mathrm{t}}=\gamma_{0}+\gamma_{1} v_{\mathrm{t}-1}+\gamma_{2} v_{\mathrm{t}-2}+\gamma_{3} \pi_{\mathrm{t}}+\gamma_{4} \pi_{\mathrm{t}-1}+\gamma_{5} \Delta \mathrm{m}_{\mathrm{t}-1}+\gamma_{6} \Delta \mathrm{m}_{\mathrm{t}-1}
\end{aligned}
$$

in Table 6 we show the 3SLQ estimates of the model described by equation (3.1). The first column contains the estimates of an unrestricted model and the second column a restricted form obtained by sequentially eliminating insignificant terms using a F-test. The most striking feature is that little is left of the BM model. Once the simultaneity has been taken account of, causality appears to flow largely from inflation to the variability of relative prices. However, lagged skewness is marginally significant so some of the

\section{Table 5}

\section{The Contemporaneous Correlation Matrix}

\begin{tabular}{|l|c|c|c|c|c|}
\hline & $u$ & $\pi$ & $\sigma$ & $v$ & $\sigma \cdot v$ \\
\hline$u$ & 1.000000 & & & & \\
\hline$\pi$ & -0.231049 & 1.000000 & & & \\
\hline$\sigma$ & -0.157125 & 0.512333 & 1.000000 & & \\
\hline$v$ & -0.115156 & 0.176995 & -0.008178 & 1.000000 & \\
\hline$\sigma v$ & -0.085610 & 0.572123 & 0.674892 & 0.437783 & 1.000000 \\
\hline
\end{tabular}


insights of the BM model still remain. The results suggest that monetary innovations do not affect either the standard deviation or skewness of relative prices, but that inflation impacts on the standard deviation of relative prices immediately and with a lag on skewness. On the other hand in terms of narrow goodness of fit the equation for inflation in Table 6 has a much

Table 6

\section{Joint Estimates}

\begin{tabular}{|c|c|c|c|c|}
\hline & \multicolumn{2}{|c|}{ Unrestricted M odel } & \multicolumn{2}{|c|}{ Restricted M odel } \\
\hline & Coefficient & t-stat & Coefficient & t-stat \\
\hline$\alpha_{0}$ & -0.1599 & -0.48 & -0.2262 & -1.82 \\
\hline$\alpha_{1}$ & 0.7956 & 6.61 & 0.6904 & 9.88 \\
\hline$\alpha_{2}$ & -0.1529 & -2.81 & -0.1477 & -5.53 \\
\hline$\alpha_{3}$ & -0.2437 & -1.70 & & \\
\hline$\alpha_{4}$ & 0.2443 & 2.00 & & \\
\hline$\alpha_{5}$ & -0.0159 & -0.03 & & \\
\hline$\alpha_{6}$ & 0.4033 & 1.04 & 0.1682 & 1.80 \\
\hline$\alpha_{7}$ & 0.0214 & 0.30 & & \\
\hline$\alpha_{8}$ & -0.0451 & -0.75 & & \\
\hline$\alpha_{0}$ & 1.1135 & 1.34 & 1.4225 & 2.95 \\
\hline$\beta_{1}$ & 0.8449 & 6.47 & 0.7135 & 8.62 \\
\hline$\beta_{2}$ & -0.1306 & -1.01 & & \\
\hline$\beta_{3}$ & 0.4194 & 1.41 & 0.6368 & 3.08 \\
\hline$\beta_{4}$ & -0.2494 & -0.85 & -0.4444 & -2.25 \\
\hline$\beta_{5}$ & -0.0414 & -0.14 & & \\
\hline$\beta_{6}$ & 0.1538 & 0.54 & & \\
\hline$\gamma_{0}$ & -0.5293 & -1.51 & -0.1881 & -1.23 \\
\hline$\gamma_{1}$ & 0.4594 & 3.66 & 0.4159 & 3.67 \\
\hline$\gamma_{2}$ & -0.1210 & -0.89 & & \\
\hline$\gamma_{3}$ & 0.0480 & 0.37 & & \\
\hline$\gamma_{4}$ & 0.0675 & 0.53 & 0.0810 & 2.14 \\
\hline$\gamma_{5}$ & 0.1486 & 0.95 & & \\
\hline$\gamma_{6}$ & -0.0288 & -0.20 & & \\
\hline$R^{2}$ & & & & \\
\hline SEE & & & 1.0 & \\
\hline DW & & & & \\
\hline
\end{tabular}

Notes: Instruments: $\sum_{\mathrm{i}=1}^{4} \mathrm{t}_{\mathrm{t}-\mathrm{i}}, \sum_{\mathrm{i}=1}^{4} \mathrm{~m}_{\mathrm{t}-\mathrm{i}}, \sum_{\mathrm{i}=1}^{4} \mathrm{t}-\mathrm{i}, \sum_{\mathrm{i}=1}^{4} \mathrm{t}-\mathrm{i}, \sum_{\mathrm{i}=0}^{4} \mathrm{u}_{\mathrm{t}-\mathrm{i}}$. 
larger standard error than that obtained earlier. Experimentation with alternative sets of instruments did not alter the basic thrust of the results.

\section{Conclusions}

We have provided some evidence for the J apanese economy on the appropriateness of the Ball-M ankiw model of relative price variability. However, the results are sensitive to the method used. Using regression techniques, as do Ball and $\mathrm{M}$ ankiw, we find evidence to suggest that the standard deviation of relative inflation matters less for inflation than skewness and the product term in skewness and standard deviation. However, the results are not as clear-cut as those that B all and M ankiw obtain for the US. This may be due to the much larger number of annual product prices they use as well as the period 1948 to 1989 . The sample that we have used for J apan is for a much smaller sample period (though on quarterly data) which is strongly influenced by the experience of 1979/ 1980 when oil prices rose. However, when we employed Granger-Causality tests we found quite the opposite. Inflation 'Granger-Causes' but is not 'Granger-Caused' by the variability of relative prices. Turning finally to a simultaneous model of inflation and the measures of relative price dispersion, our results are much less favourable to the BM model. M uch of the causality appears to flow from inflation to the standard deviation of relative prices, and with a lag to skewness. On the other hand, only skewness lagged has a marginally significant effect on inflation.

\section{References}

Ball L. and N.G. M ankiw [1995], "Relative-Price Changes as Aggregate Supply Shocks," Quarterly Journal of E conomics, 60; pp. 161-193.

Batchelor, R.A [1981], "Aggregate Expectations under the Stable Law," Jour nal of E conometrics, 16; pp. 199-210.

Balk, B.M [1978], "Inflation and Its Variability: Some Comments on the Dutch Case," Economic Letters, 1; pp. 357-60.

B lejer, M .I. [1983], "On the Anatomy of Inflation: the Variability of Relative Commodity Prices in Argentina," Journal of M oney, Credit and Bank - 
ing, 15, N ovember; pp. 469-482.

Bordo, M. D. [1980] "The Effects of M onetary Change on Relative Commodity Prices and the Role of Long Term Contracts," Journal of Politi cal Economy, 88, December; pp. 1088-1109.

Buck, A. J. and B. Gahlen [1983], "On the Normality of Relative Price Changes" E conomic Letters, 113; pp. 231-236.

Clements, K.W. and P. Nguyen [1981], "Inflation and Relative Prices: the Australian Experience," Mimeo, The Reserve Bank of Australia, Sidney.

Cukierman, A. [1979], "The Relationship between Relative Prices and the General Price Level: a Suggested Interpretation," American E conomic Review, 69, No. 3; pp. 444-447.

Cukierman, A. and Wachtel [1979], "Differential Inflationary Expectations and the Variability of the Rate of Inflation: Theory and Evidence," American E conomic Review, 69; pp. 595-609.

Fischer, S. [1982], "Relative Price Variability and Inflation in the US and Germany," European Economic Review, 18; pp. 171-196.

Frenkel, J.A. [1982], "Relative Price Variability and Inflation in the US and Germany: A Comment," European E conomic Review, 18; pp. 97-105.

Glejser, H. [1965], "Inflation, Productivity and Relative Prices - a Statistical Study," Review of E conomics and Statistics, 47, Feb.; pp. 76-80.

Graham, F.D. [1930], Exchange, Prices and Production in Hyper-inflation: Germany, 1920-23, Princeton University Press, Princeton, NJ.

Herkowitz, Z. [1981], "M oney and the Dispersion of Relative Prices," Jour nal of Political Economy, April; pp. 328-356.

Lilien, D.M . [1982], "Sectoral Shocks and Cyclical Unemployment," Journal of Political Economy, 90, August; pp. 777-793.

Logue, D.E. and T.D. Willett [1976], "A N ote on the Relationship between the Rate and Variability of Inflation," E conomica, 43; pp. 151-158.

Mills, F. [1927], "The Behavior of Prices," National Bureau of Economic Research, New York.

M izon, G.E., J.C. Safford and S.H. Thomas [1990], "The Distribution of Consumer Price Changes in the United Kingdom," E conomica, 57, M ay; pp. 249-262.

Parks, R.W. [1978], "Inflation and Relative Price Variability," Journal of Politi - 
cal Economy, 86; pp. 79-96.

Reinsdorf, M . [1994], "New Evidence on the Relation between Inflation and

Price Dispersion," American Economic Review, 84, 3; pp. 720-731.

Schultze, C.L [1959], "Recent Inflation in the United States," Study Paper

No. 1, Prepared for the Joint Economic Committee of the US Congress, September.

Sheshinski, E and Y. Weiss [1981], "Inflation and the Costs of Price Adjustment," Review of E conomic Studies, 64; pp. 287-303.

Tobin, J. [1972], "Inflation and Unemployment," American E conomic Review, M arch; pp. 1-18.

Vining, D.L. and T.C. Elwertowski [1976], "The Relationship between Relative Prices and the General Price Level," American E conomic Review, 66; pp. 699-708.

Taylor, J. [1981], "On the Relationship between the Variability of Inflation and the Average Inflation Rate," Carnegie-Rochester Conference Series on Public Policy, 15; pp. 57-85.

Tsiddon, D. [1991], "On the Stubbornness of Sticky Prices," Intemational Economic Review, 32, February; pp. 69-75.

Tsiddon, D. [1993], "The (M is) Behavior of the Aggregate Price Level," Review of Economic Studies, 60, October; pp. 889-902. 